\title{
Review of: "Effect of Copper Donor Material Assisted Friction Stir Welding of AA6061-T6 Alloy On Downward Force, Microstructure, And Mechanical Properties"
}

\author{
Mehran Tamjidy
}

Potential competing interests: The author(s) declared that no potential competing interests exist.

In this paper, the authors studied the effect of copper donor material assisted friction stir welding of AA6061-T6 alloy on downward force, microstructure, and mechanical properties. They have examined a combination of joints using $\mathrm{Cu}$ donor material of different thickness. From the results it seems that this work needs more experiments to extent. My suggestions are given as follows:

1. The literature review is not broad enough to include resent researches in the field.

2. It is required to indicate the configuration and dimension of tensile and hardness specimens.

3. Regarding the title of this paper, how these extracted specimens can specify the effect of using donor material in terms of mechanical and microstructure properties in welded zone.

4. It is mentioned that industries can take the advantage of using this method to increase the tool life, but there is no experiments to show the results of tool wear ratio with and without using this method. Furthermore it is suggested to compare the tool wear ratio result with other research.

5. How can this method possibly be cost effective in terms of tool consuming in which it can be observed this method may cause more time and machinery? 